\title{
Research on Agricultural Information Data Based on Knowledge Mapping
}

\author{
Fu Ning ${ }^{1, a}$ and HuiPeng $Y u^{2, b}$ \\ No.77,Hanlin Road, Economic and Technological Development District,Jilin prov. \\ Northeast Normal University affiliated primary school prosperity campus, Changchun, Chaoyang \\ District prosperity Road, No. 8 \\ a jlnyedu@163.com ${ }^{\text {b }}$ arm9linux@163.com
}

Keywords: Agricultural informatization; Citation Analysis; Knowledge map; Citespace

\begin{abstract}
The main research contents of this paper include the following two parts: In the first part, the form characteristic of data source is analyzed. Through the analysis of the distribution of published papers can be found from 2001, 2002 and 2003 are only 1 articles in HowNet data platform, from the beginning of 2004, the number of the papers in HowNet has made great improvement, in 2009, appeared sharp change trough, until 2015, the number of steady growth in the academic literature.

The second part analyzes the content of the data source. According to "Jilin Province agricultural informatization" as the knowledge map of 91 papers, the theme of retrieved 330 journal papers drawn through the analysis of the response to "Jilin agricultural information", "Jilin Province agricultural information", "three rural issues in Jilin", "Jilin Province, information technology, information service in Jilin Province", "Jilin Province Information Resources", "Jilin GIS", "Jilin agricultural modernization" is the focus of the study.
\end{abstract}

\section{Introduction}

Based on the existing foundation and development trend of agricultural informatization in Jilin province, with regard to the "agricultural information" of Jilin Province, the master's thesis, journal papers for the data source, the present situation of agricultural informatization in China is sorted out by using the knowledge map, which provides reference and guidance for the development of agricultural informatization in Jilin province.

\section{The Paper's Main Purpose and Significance}

1. the concept of agricultural informatization and the definition of data collection

Collect authentic and valid data materials and establish the scope of collection.

2. construct a knowledge map.

(1) consulting the literature, collecting data of CNKI and Wanfang Data platform.

(2) analyze the result and get the hot spot and development trend of agricultural informatization in Jilin province with Citespace.

(3) construct the knowledge map of agricultural production informatization, agricultural management information, agricultural management informatization and agricultural service informatization respectively.

\section{Introduction of Knowledge Domains map}

Because of the knowledge map is studied by means of measuring technology which is based on the method of knowledge map, so the category belongs to the field of scientometrics, this dissertation mainly uses scientometrics bibliometrics and common data visualization map of Jilin province agriculture information related to research, from the CNKI and the same database data in detail data acquisition, information processing, data visualization and statistical processing, the main research direction of agricultural informatization in Jilin province and the progress is displayed, so as to 
reveal the dynamic development rules in this field, and provide valuable reference data for further research, accurate agricultural information science

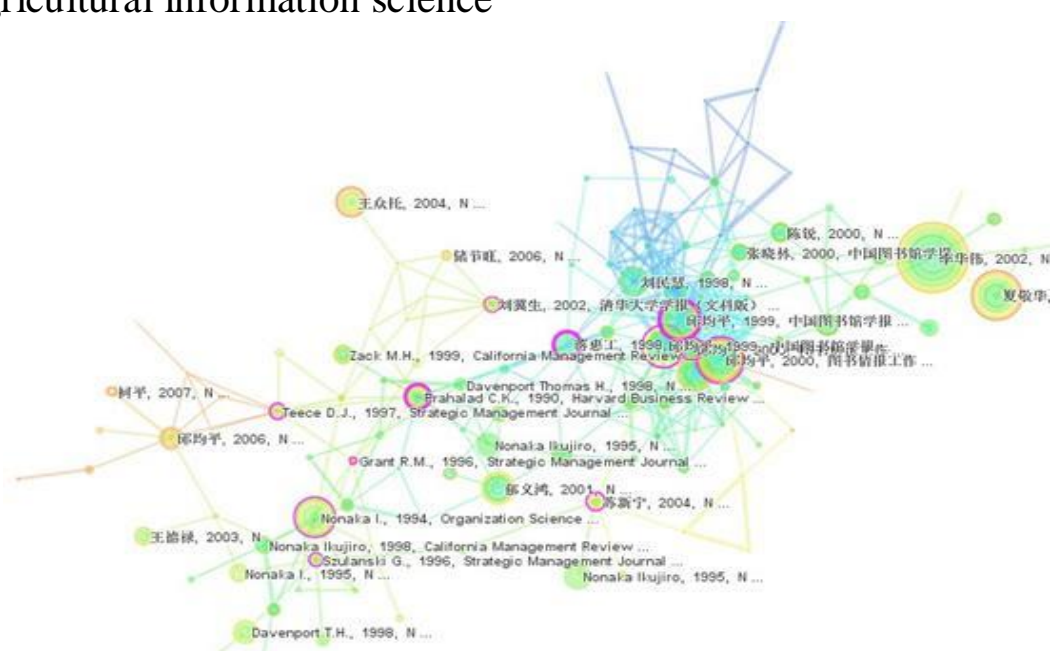

Figure 1.Agricultural informationization agency distribution of knowledge domains map

\section{Knowledge map Based on Content Analysis of CNKI Database}

For data analysis, different keywords, using the results of Citespace software analysis inconsistent, different results will lead to different coping measures. Therefore, it is very important to analyze the key points of the data analysis of the papers and periodicals.

\section{High Frequency Keywords Contrast Analysis}

Retrieval of CNKI data can be seen from the table, the number of search on the "Jilin agricultural information" (theme retrieval) most times, so the data analysis is mainly carries on the detailed analysis of the "Jilin agricultural information", "in order to reflect more accurately the agricultural informationization of Jilin province" and other key words of the relationship between [42]. Pathfinder algorithm using CitespaceIII, research keywords on the doctor and master the map analysis, network node data analysis is set to "Keyword", the selected words choose the top 40 keywords, to generate knowledge map of frequency, as shown in Figure 4.1, where nodes represent each of the keywords of agriculture in Jilin province information".

Table 1 High frequency keywords contrast analysis

\begin{tabular}{|c|c|c|c|c|c|}
\hline $\begin{array}{c}\text { Seria } \\
1\end{array}$ & & number & Serial & & number \\
\hline 1 & $\begin{array}{l}\text { agricultural } \\
\text { informatization in Jilin }\end{array}$ & 82 & 9 & Jilin agriculture & 67 \\
\hline 2 & $\begin{array}{l}\text { agricultural information } \\
\text { of Jilin province }\end{array}$ & 91 & 10 & $\begin{array}{l}\text { Jilin information } \\
\text { technology }\end{array}$ & 45 \\
\hline 3 & Jilin three rural issues & 38 & 11 & $\begin{array}{l}\text { information service of } \\
\text { Jilin province }\end{array}$ & 71 \\
\hline 4 & $\begin{array}{l}\text { Jilin provincial } \\
\text { information technology }\end{array}$ & 43 & 12 & $\begin{array}{l}\text { modern agriculture in } \\
\text { Jilin province }\end{array}$ & 21 \\
\hline 5 & $\begin{array}{l}\text { information service of } \\
\text { Jilin province }\end{array}$ & 39 & 13 & $\begin{array}{l}\text { Jilin informatization } \\
\text { mode }\end{array}$ & 35 \\
\hline 6 & $\begin{array}{l}\text { information resources of } \\
\text { Jilin province }\end{array}$ & 67 & 14 & $\begin{array}{l}\text { informatization of } \\
\text { Jilin province }\end{array}$ & 29 \\
\hline 7 & Jilin province GIS & 15 & 15 & $\begin{array}{l}\text { Jilin agricultural } \\
\text { modernization }\end{array}$ & 37 \\
\hline 8 & $\begin{array}{l}\text { agricultural } \\
\text { modernization in Jilin }\end{array}$ & 58 & 16 & $\begin{array}{l}\text { Jilin agricultural } \\
\text { interconnection }\end{array}$ & 46 \\
\hline
\end{tabular}




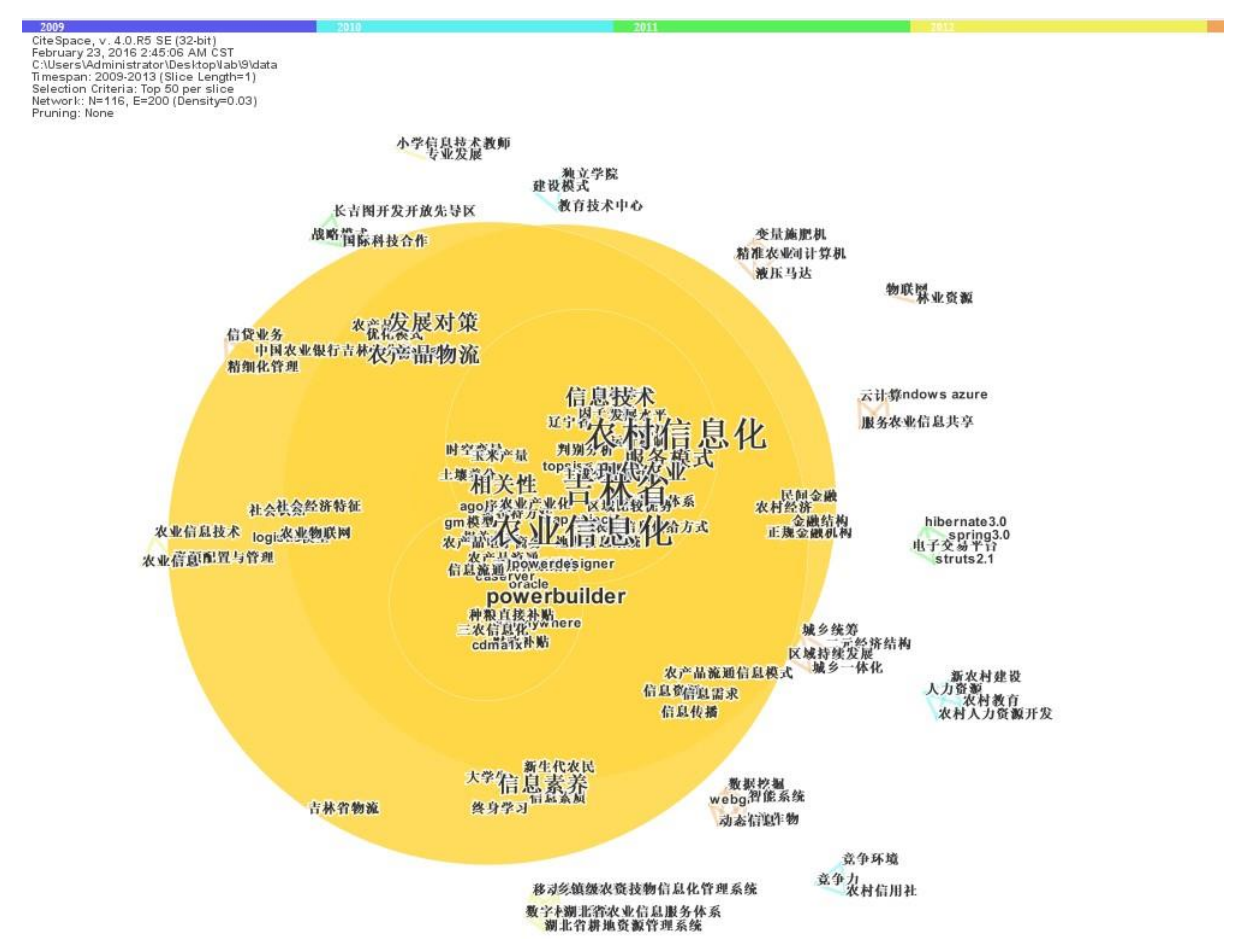

Fig. 2. 2009 -2013 Keywords frequency knowledge map

From 2009 to 2013, the key words of knowledge map can be seen, words related to Jilin agricultural informatization increased significantly, research on information technology and the specific agriculture related industries, have gradually increased, for example: related research of agricultural products, agricultural soil, financial structure appear in the map, obviously, can be seen, compared to research on agriculture the information of the past, Jilin Province in the process of the development of agricultural information to affect the specific impact of the development of agricultural information factor is researched in detail, and the overall integration of development ideas of Jilin agricultural information, and have made certain achievements.

\section{Conclusion}

The basic theory analysis results and the previous chapters through the above Citespace data, it can be concluded that the development of agricultural information in Jilin province mainly from Research Institute of universities and scientific research institutes, the research focus mainly summarized three aspects: modernization, diversification and automation development trend.

Modernization. From the Citespace display data processing results, we can see the development process of Jilin Province agricultural informatization presents the steady growth in the number of research trends, before $2002 \mathrm{CNKI}$ is retrieving data for 0, 2016 to retrieve data (accurate) reach 421 documents (including 330 articles published literatures, 91 papers), in observational data it can be seen that the degree of association of Jilin province and the agricultural informatization is most closely.

Diversification. In the data processing and display results, we can clearly see that researchers (universities or research institutes) have more research areas, showing a trend of diversification. But the diversification mentioned here not only refers to the diversification of the research field, but also shows the trend of interdisciplinary development in the research methods as well as in the provincial project.

Automation. With the development of national industry and the 4 Internet plus concept, the impact of information technology has not only affect the development of industry related industries, but has affected all aspects of agricultural development. For the automation of agricultural development also raises new requirements, extracted from CNKI data correlation analysis can be seen in Citespace, are introduced and analyzed in detail the papers and periodicals in Jilin Province universities and research institutions are on the development of agricultural automation. 


\section{References}

[1]Chen C.Searching for intellectual turning points:Progressive knowledge domain visualization [J]. PNAS,004,101(1):5303-5310.

[2]Grossman, S.and Hart, O. An Analysis of the Principal-agent Problem, Econometrica, 1983(51): $7-45$.

[3] Holmstrom, B. Moral Hazard and Observability, Bell Journal of Economics, 2011(10)74-91.

[4]Henry Small .Co-citation in the Scientific Literature: A New Measure of the Relationship Between Two Document [J].Econometrica,2011,(55):251 -276.

[5]Chen Chaomei, Ibekwe-SanJuan F,Hou Jianhna. The structureand dynamics of co-citation clusters: A multiple -perspective co -citation analysis [J]. Journal of the American Society for Information Science and Technology,2010,61 (7): 1386-1409.

[6]E.Garfield.Citation Indexes for Science: A New Dimension in Documentation through Association of Ideas[J]. Science,2013,122:108-111. 